\title{
Uma introdução ao Empirismo Alternativo de David Hume
}

\section{Introducción al Empirismo Alternativo de David Hume}

\section{An introduction to the Alternative Empiricism of David Hume}

\author{
Daniel Soares Mano Gonçalves \\ ${ }^{a}$ Mestre e Doutor em Ciência Política pela Universidade Federal Fluminense. Docente dos cursos de MBE do Laboratório de Responsabili- \\ dade Social e Sustentabilidade (LARES) na Universidade Federal do Rio de Janeiro, Rio de Janeiro/RJ, Brasil. dan_soci@yahoo.com.br
}

Resumo: Neste artigo, sustento que o conjunto da obra de David Hume pode ser compreendido como expressão de uma reelaboração singular e original, a seu tempo, da tradição empirista que encontrou em John Locke seu principal artífice. Procuro identificar as particularidades e analisar os desdobramentos dessa concepção alternativa do empirismo naqueles que considero os três aspectos fundamentais do pensamento humeano: o entendimento, as paixões e a moral. Pretendo, ainda, com esta investigação, salientar o papel do empirismo humeano como um dos eixos integradores de sua filosofia.

Palavras-chave: Empirismo; Iluminismo escocês; David Hume.

Resumen: En este artículo, sostengo que toda la obra de David Hume puede ser entendida como expresión de una singular y original reelaboración, en su momento, de la tradición empirista que encontró John Locke como su principal artífice. Intento identificar las particularidades y analizar los desarrollos de esta concepción alternativa del empirismo en los que considero los tres aspectos fundamentales del pensamiento humeano: comprensión, pasiones y moral. También pretendo, con esta investigación, destacar el papel del empirismo humeano como uno de los ejes integradores de su filosofía.

Palabras-clave: Empirismo; Ilustración escocesa; David Hume

Abstract: In this article, I argue that the whole of David Hume's work can be understood as an expression of a unique and original reworking of the empiricist tradition that found in John Locke, its main craftsman. I try to identify the particularities and analyze the unfolding of this alternative conception of empiricism in those that I consider the three fundamental aspects of Humean thought: understanding, passions and morality. I also intend with this research to emphasize the role of Humean empiricism as one of the integrating axis of his philosophy.

Keywords: Empiricism; Scottish enlightenment; David Hume.

Como citar o artigo: MANO, D. Uma introdução ao Empirismo Alternativo de David Hume. Revista de Ciências Humanas, Florianópolis, v. 54, 2020 DOI: 10.5007/2178-4582.2020.e56185 você pode compartilhar, adaptar, para qualquer fim, desde que atribua a autoria da obra, forneça um link para a licença, e indicar se foram feitas alterações. 


\section{O EMPIRISMO DE HUME}

No extenso verbete "Empiricism" da Encyclopedia Britannica Online, lê-se que Hume "elaborou plenamente o empirismo de Locke". O escocês figura, nas páginas da publicação, e de outras do gênero, como herdeiro de uma tradição intelectual que finca raízes no mundo antigo, e que na filosofia moderna tem em John Locke seu patrono e sistematizador. Sua influência atravessa os séculos XVIII e XIX, encontrando eco em pensadores como Voltaire, Stuart Mill, Herbert Spencer, entre muitos outros.

O empirismo lockeano assume uma separação elementar, posteriormente herdada por considerável parcela do pensamento filosófico e científico, entre o sujeito de conhecimento e o conjunto de objetos que lhe é exterior - o mundo - e apreensível pelos órgãos dos sentidos. Essa distinção se faz clara quando, no Ensaio sobre o Entendimento Humano, Locke diferencia, acerca dos objetos, suas qualidades primárias das secundárias. As primeiras referem-se a atributos inerentes aos objetos, independentemente de qualquer observação por parte de seres vivos: solidez, forma, extensão e mobilidade (LOCKE, 1975, p. 135). As secundárias, por sua vez, consistem em efeitos provocados pelos objetos no momento de seu contato com o sujeito que o percebe: cores, sons, cheiros, etc.

O filósofo John Dewey, alguns séculos após Locke, denominou essa perspectiva dualista sobre o conhecimento humano de "teoria do conhecimento do espectador" (DEWEY, 1929, p. 26). A perspectiva do espectador, para Dewey, baseia-se em uma metáfora ótica: o processo de conhecimento é concebido por analogia à concepção newtoniana do processo da visão, segundo a qual objetos luminosos emitem corpúsculos (raios) recepcionados pelo olho, e transmitidos pelo órgão à mente, originando ideias. O olho assemelha-se, nesta perspectiva, a um objeto inanimado, como uma lente ou prisma, carente de atributos orgânicos e biológicos. Suas funções restringem-se à recepção, registro e condução. Os diferentes saberes, quando concebidos dessa forma, tomam a forma ideal de canais de acesso transparentes à realidade objetiva.

Essa versão do empirismo, repito, reverberou e tornou-se hegemônica no meio científico com a emergência do positivismo no fim do século XIX. Alguns intérpretes do pensamento de Hume, talvez influenciados pelas constantes referências ao estilo empirista de seu pensamento, entenderam-no, equivocadamente, a meu ver, como continuação e/ou "elaboração", na expressão acima mencionada, do empirismo lockeano. É o caso, por exemplo, de Sartre, para quem a imaginação, na visão humeana, atua sobre uma espécie de acervo ou coleção de objetos apreendidos pelos sentidos. Para Sartre (2008, p. 104), "Foi com razão que Laporte comparou Hume aos neo-realistas. Para ele, como para estes, não existem senão objetos". Popper (1972), por sua vez, ao referir-se à tradição empirista, menciona Locke, Berkeley e Hume como seus principais formuladores, e embora ressalve que suas teorias diferem em alguns pontos, identifica como traço comum a todas a ênfase nas evidências oriundas dos sentidos como árbitros da verdade ou falsidade de nossas crenças (POPPER, 1972, p. 127).

Gostaria de sustentar que, se há algum sentido em classificar a filosofia de Hume como empirista, é preciso esclarecer as diferenças fundamentais que seu empirismo apresenta em relação ao de Locke e seus herdeiros. Comecemos pelas semelhanças que podem evidenciar a adequação do termo "empirismo" a ambos os paradigmas. De fato, para Hume, assim como para Locke, o conhecimento humano, ou grande parte dele, deriva da experiência. Como bem observou Monteiro (2009, p.16), "dos empiristas, Hume conserva especialmente uma atitude metodológica: a recusa em aceitar qualquer teoria que não se submeta à prova da experiência". Ambos, ainda, rejeitam a teoria das ideias inatas, que estariam desde sempre inscritas na alma humana, por obra do Criador e atribuem papel secundário à razão no processo de conhecimento. As semelhanças, contudo, cessam aí.

O empirismo de Hume é marcado por um deslocamento radical, através do qual o conceito de "experiência" afasta-se do sentido lockeano. A experiência, para Locke, abrange os processos de sensação e reflexão. O primeiro consiste na recepção pela mente, através dos órgãos dos sentidos, dos estímulos emitidos pelos objetos componentes do mundo material. O segundo, por sua vez, envolve a associação, na mente, das ideias formadas no bojo do primeiro processo: 
Esta grande fonte da maioria das Ideias que temos, dependendo inteiramente de nossos Sentidos, e derivada por elas do Entendimento, chamo SENSAÇÃO. Em segundo lugar, a outra fonte, da qual a experiência fornece o entendimento das idéias, é a percepção das operações de nossas próprias mentes dentro de nós ... então chamo essa Reflexão (LOCKE, 1975, p. 105)

Essas duas faces da experiência baseiam-se, segundo Locke, em propriedades distintas da mente, ou sendo mais fiel à sua terminologia, a dois poderes inerentes à mente: o passivo e o ativo. $\mathrm{O}$ processo de reflexão é de natureza eminentemente ativa, no sentido de que a mente é capaz de deflagrar atos volitivos internos - as operações mentais do raciocínio designadas por Locke (1975, p. 105): "perceber, pensar, duvidar, acreditar, raciocinar, conhecer, desejar". Como notou Aldrich (1933, p. 247), para Locke "A mente é ativa, pois possui o poder de iniciar movimento", em contraste com os objetos encontrados no mundo material, cujo movimento resulta necessariamente do choque com outros objetos. A dimensão sensorial da experiência (o processo da sensação), por seu turno, encontra-se calcada em outro tipo de poder, o poder passivo, definido por Locke como a capacidade de receber transformações oriundas de algum agente externo: "O poder assim considerado é duplo, viz. capaz de fazer ou receber qualquer alteração” (LOCKE, 1975, p. 234).

Parcela considerável da experiência em Locke, portanto, pode ser atribuída ao aspecto passivo da mente - a "maioria das ideias que temos", como na passagem reproduzida acima. Locke indica em diversas passagens essa dimensão passiva que subjaz no contato entre mente e mundo, mediado pelos órgãos dos sentidos: "Pois na Percepção nua e crua, a Mente é, no mais das vezes, apenas passiva; e o que percebe, não pode evitar perceber”(LOCKE, 1975, p. 143); “a Mente é totalmente passiva na recepção de todas as suas idéias simples” (LOCKE, 1975, p. 163); "Que a Mente, em relação às suas Idéias simples, é totalmente passiva e recebe-as todas da Existência e Operações da Coisas ... a Experiência nos mostra" (LOCKE, 1975, p. 288).

Assim, enquanto em Locke, é possível encontrar com frequência a noção de um mundo já pronto, acabado, que se dá a perceber e é meramente registrado por uma mente passiva, em Hume, a dimensão passiva da mente encontra-se praticamente ausente; a experiência humeana diz respeito a uma mente essencialmente ativa, que confere sentido ao que é percebido pelos sentidos, não se constituindo como depósito de objetos (ou mais propriamente, de suas imagens). A radicalidade da perspectiva humeana foi sintetizada com precisão por Berlin (1999, p. 39):

Quando ele [Hume] perguntou-se como sabia que havia um mundo externo, ele disse que não poderia deduzir isso logicamente: não havia maneira de demonstrar que cadeiras existiam ... Por isso, devo aceitar o mundo como matéria de crença.

Esse aspecto de sua filosofia foi realçado também por Price (1940) ao investigar as reflexões de Hume sobre a existência do mundo exterior, especialmente em sua análise do que denomina "teoria construtiva da percepção" (PRICE, 1940, p. 133) presente no Tratado da Natureza Humana. Ao comentar as afinidades entre as concepções de Imaginação de Hume e Kant, Price observa que "ambos sustentam que o mundo fenomênico, o mundo dos objetos materiais e do eu empírico é, em certo sentido, uma construção imaginativa" (PRICE, 1940, p. 16). Price enfatiza a natureza suplementar e sintética que a Imaginação assume na filosofia humeana; ela seria a principal responsável por preencher as lacunas e interrupções que caracterizam a experiência ordinária, ou seja, por dotar de algum grau de inteligibilidade e coerência um domínio originalmente fragmentário, disperso: "Sem suas [da Imaginação] atividades de síntese e suplementação, devemos estar cientes de nada além de um fluxo de impressões sensoriais; nós nem devemos estar cientes de que o fluxo é um fluxo e de que tem uma ordem temporal" (PRICE, 1940, p. 16).

Os homens, para Hume, são atravessados por impressões de maneira incontornável, isto é, são seres sensíveis que, desde o início de sua existência, encontram-se imersos no fluxo incessante da 
experiência. Não estão, portanto, apartados do "mundo exterior", ao menos não da forma categórica com que o empirismo lockeano propôs essa dualidade. Podemos afirmar, portanto, que não há solução de continuidade natural entre homem e mundo, para Hume: o homem está no mundo, e o mundo está no homem. A dualidade, tão cara ao pensamento de Locke e a tantos outros, e tão comum na linguagem cotidiana se estabelece artificialmente, ou seja, por um artifício da natureza humana e suas faculdades. Em resumo, a mente humana engendra a separação entre sujeitos e objetos, a partir do fluxo de impressões que experimenta, mas a aposta fundamental da teoria de Hume, que a distancia notavelmente do empirismo hegemônico e torna-a radicalmente singular, consiste em afirmar a natureza fabricada dessa dualidade. A mente humana não é mais apenas um repositório de percepções prontas, mas um princípio ativo, de construção, reconstrução e destruição de realidades.

Uma vez esclarecida essa particularidade do empirismo humeano, nas próximas seções, buscarei apresentar as linhas gerais desse modelo, assim como alguns possíveis vínculos entre os três grandes eixos de seu ambicioso projeto de construir uma ciência da natureza humana. Esses eixos correspondem aos três livros de sua Magnum Opus, o Tratado da Natureza Humana: o entendimento, as paixões e a moral.

\section{O ENTENDIMENTO}

Além das singularidades acima mencionadas, o estilo humeano destaca-se pela frequente recusa ao estabelecimento de definições precisas e detalhadas. É comum encontrar, principalmente ao longo de sua primeira e mais densa obra, o aludido Tratado, afirmações sumárias como "Cada um, por si mesmo, percebe imediatamente a diferença entre sentir e pensar" (HUME, 2000, p. 25) ou, "sendo obrigado a apelar para aquilo que cada um sente, a fim de lhe dar uma noção perfeita dessa operação da mente [a crença]" (HUME, 2000, p. 126). Arruda (2014), em recente estudo, sustentou que a ausência de definições em diversos momentos do Tratado não decorreu de desleixo ou carência de rigor por parte do escocês, mas de uma opção metodológica, diante de fenômenos que mesmo as mais rigorosas definições não conseguiriam descrever a contento - na verdade, seriam prejudiciais à sua compreensão.

Hume utiliza, por diversas vezes, o diálogo com seus leitores como recurso para lidar com questões que a radicalidade de seu empirismo tornam de difícil formulação e comunicação. Ao passo que o empirismo lockeano tem sua tarefa facilitada pela concepção de um mundo pronto passível de ser conhecido, ainda que indiretamente, Hume lida com problemas mais fundos e indistintos, como o das impressões. De fato, a teoria da percepção de Locke, como notou Aldrich (1933, p. 257) possui caráter causal e representacional: as ideias primárias, como solidez, forma, extensão e mobilidade, assemelham-se a certas qualidades dos objetos, representando-as na mente. A descrição lockeana desse processo recorre, com frequência, ao lastro da realidade objetiva, de onde emanam os estímulos que afetam a mente, como as partículas de luz, no caso da visão ou o contato corporal, no caso do tato. Os órgãos dos sentidos, no modelo lockeano, realizam a interface entre as dimensões material (os objetos externos) e imaterial (a mente), como assinala Aldrich (1933, p. 255):

E como o contato da matéria com a mente ocorre na região dos órgãos dos sentidos, os órgãos dos sentidos podem ser descritos como a matéria que surge na mente ou como a mente que se junta à matéria, para tornar possível a causalidade entre eles.

Hume, por contraste, não conta com esse lastro epistemológico, como revelam suas objeções céticas à postulação inequívoca de um mundo externo e independente dos sentidos, encontradas, sobretudo na seção "Do ceticismo em relação aos sentidos" do Tratado. Entre os reflexos mais notáveis desse aspecto de sua filosofia encontra-se a perda de fundamento da teoria causal e representacional da percepção, tal como encontrada em Locke. Malherbe (2001) apontou a singularidade da noção humeana 
de "impressão" no contexto da tradição empirista, uma vez que despida da natureza eminentemente fisiológica de seu correspondente em Locke, a "sensação". Enquanto esta última resulta, para Locke, de estímulos externos produzidos nos órgãos sensoriais, para Hume, a impressão se constitui como um "sentir" intransitivo, uma experiência da mente (ou alma) originada de "causas desconhecidas" (HUME, 2000, p. 32). Hume não desconsidera de todo os aspectos fisiológicos, sobretudo quando recomenda o estudo das impressões sensoriais (as impressões de sensação) aos anatomistas (HUME, 2000, p.32), mas trata-se de comentário lateral, filosoficamente despretensioso ${ }^{1}$ e distante do cerne da "experiência-impressão" (MALHERBE, 2001, p. 91) que Hume busca por vezes delinear, isto é, a impressão em si mesma, em sua dimensão mais básica e elementar. Quando as considera dessa perspectiva, as impressões são:

nem uma ideia confusa, nem mesmo um embrião de ideia: ela é sentida. Falando por metáfora, é o mesmo de quando, sob o efeito de uma luz muito bruta, muito branca, as coisas são apresentadas aos olhos com tanta clareza e violência, que a própria visão é como que destruída e todas as formas abolidas em uma percepção totalmente investida pelo ser do mundo. (MALHERBE, 2001, p. 99)

No modelo humeano, impressões e ideias assumem a condição de fundamentos, marcos zero sobre os quais se ergue todo o seu sistema. Hume os define como os dois grandes gêneros da percepção humana, mas não se deve confundi-los com os objetos que representam - e, por objetos, refiro-me tanto a objetos físicos, como mesas e árvores como a objetos imateriais, como sentimentos e estados de consciência. Os objetos que percebemos, por certo, são percebidos na forma de impressões e ideias, ou seja, não há modo de perceber o mundo, a não ser pelos veículos perceptivos básicos: impressões e ideias. É possível, no entanto, diferenciar estas últimas dos supostos objetos que elas reproduzem em nossas mentes. A crença na existência do mundo externo e de todos os seus elementos requer um grau considerável de conceituação, de operações sutis e imperceptíveis, porém complexas, da mente humana. Já as impressões e ideias são, no princípio, elementos brutos, sem forma e sentido bem definidos, pura expressividade, e só adquirem sentido e conteúdo substantivo no decurso da experiência.

Como se vê, Hume investe esses fenômenos perceptivos de sensível complexidade, pois impressões e ideias, em estado bruto, são experiências das quais os homens comuns não possuem lembranças. A solução encontrada por Hume para definir fenômenos tão fugidios consiste, como assinalei, em recorrer à experiência pessoal do leitor; muito embora não se encontrem aí impressões e ideias em sua configuração primária e crua, parece evidente a Hume que todos os seres humanos são capazes de identificar traços comuns entre dois modos de percepção: o sentir e o pensar. Em meio à multiplicidade de percepções - aquilo que se vê, ouve, cheira, sente -, Hume apela a nós, para que percebamos um grau comum de "força e violência" (HUME, 2000, p. 25) que as torna partícipes de um mesmo gênero perceptivo, o das impressões, isto é, o domínio do sentir.

As impressões, portanto, podem ser descritas como um modo intenso, forte e vívido de percepção. As ideias, por sua vez, ou o domínio do pensar, constituem versões empalidecidas dessas mesmas impressões; são, por assim dizer, reflexos esmaecidos das impressões originárias que perduram na mente. Entre impressões e ideias, convém observar, Hume estabelece um princípio de anterioridade das primeiras em relação às segundas, ou seja, não há ideia que não derive de uma impressão anterior, de modo que a crença em ideias inatas, existentes desde sempre na alma humana, não encontra lugar em seu modelo.

As impressões, ao se converterem em ideias na mente, podem reter alguma parcela de sua vividez original, "constituindo-se em uma espécie de intermediário entre uma impressão e uma ideia" (Hume,

1 Eis uma característica típica do estilo humeano, a despretensão, que se manifesta mesmo na investigação de temas complexos e obscuros, como assinala Price (1940, p. 3): "Ele [Hume] escreve em um tom leve e zombeteiro, mesmo quando está discutindo os problemas mais profundos". 
2000, p. 33). Nesse caso, é a faculdade da memória a responsável por esse avivamento parcial das ideias, que por vezes nos faz sentir um evento passado como se estivesse acontecendo no presente. Já quando as ideias "perdem inteiramente aquela vividez, tornando-se uma perfeita ideia" (HUME, 2000, p. 33), é a faculdade da imaginação que a evoca, de forma lânguida, fraca. Repare-se que as duas principais faculdades da mente, memória e imaginação, à semelhança dos dois modos de percepção, impressões e ideias, não são definidas de forma categórica e precisa por Hume; antes, o filósofo as define, mais uma vez, em termos comparativos, ou seja, quanto à força e vividez com que cada uma dessas faculdades reproduz as outrora impressões em nossas mentes. Essa diferença pode ser atestada, julga Hume, como no caso anterior, por qualquer leitor de boa fé que se disponha a analisar a própria experiência pessoal.

As fronteiras entre essas faculdades, convém assinalar, não são determináveis com exatidão. Ideias da imaginação, por vezes, obtêm tamanha verossimilhança, que podem aproximar-se de ideias de memória, como no clássico caso do mentiroso que passa a acreditar nas próprias mentiras; o inverso, por sua vez, também é possível: memórias, normalmente as mais remotas, que progressivamente perdem sua força, aproximando-se de ideias da imaginação.

Do que foi exposto até aqui, pode-se pensar que o conceito de imaginação em Hume aproxima-se do sentido usual do termo, que se fixou na linguagem cotidiana, como a faculdade através da qual os homens podem representar a si mesmos, combinar e recombinar livremente suas ideias, dando "asas à imaginação". Esse sentido não se restringiu, em verdade, ao senso comum; de fato, no âmbito da filosofia moderna, encontramos mais ou menos explicitamente a mesma concepção. Para Descartes (2005, p. 47), "imaginar não é outra coisa senão contemplar a imagem ou a figura de uma coisa corporal"; além do ato de contemplar, uma imaginação extravagante pode, por recombinações de ideias, "inventar algo de tão novo que jamais tenhamos visto nada de semelhante" (DESCARTES, 2005, p. 34), como os monstros extraordinários das ficções e mitologias. Locke, no mesmo sentido, separa categoricamente os processos da imaginação e do conhecimento: este último dependeria de uma "conformidade entre nossas ideias e a realidade das coisas" (LOCKE, 1975, p. 563), enquanto o primeiro permanece limitado às representações mentais, assemelhadas a "sonhos", "fantasias" e "castelos de ar" quando carentes de lastro objetivo, nas coisas mesmas.

O conceito de imaginação em Hume, ao passo que retém algo do significado conferido pela linguagem cotidiana e pelas filosofias de Locke e Descartes, amplia consideravelmente seu escopo, tornando-o não apenas uma faculdade trivial, de representação livre das ideias, antinômica em relação ao conhecimento verdadeiro. A imaginação, segundo Hume, atua como princípio de construção do conhecimento humano, de ordenamento e vertebração das experiências confusas e multiformes que nos assaltam desde que passamos a existir. Como Descartes e Locke, Hume reconhece seu caráter combinatório, pois, ao imaginarmos, com frequência unimos e desunimos ideias, mas à diferença dos primeiros, Hume não vê a imaginação como o território apenas da combinação livre e desimpedida; esta é possível, em algumas ocasiões, mas em muitas outras, impera aquilo que Hume denomina qualidades associativas, tendências presentes na imaginação a associar certas ideias, de modo que "uma ideia naturalmente introduz outra" (HUME, 2000, p. 34). Caso não existissem essas "forças suaves" de associação, "Fossem as ideias soltas e desconexas, apenas o acaso as juntaria" (HUME, 2000, p. 34), e as mentes humanas tomariam a forma de um caos de ideias claras, na célebre expressão de Émile Faguet $^{2}$ a respeito do pensamento de Voltaire.

Ao distanciar-se da noção lockeana de um mundo objetivo, independente da percepção humana, Hume encontra na imaginação o agente capaz de costurar as impressões e ideias, de maneira que seu modelo não resulte em uma reductio ad absurdum, à concepção de seres humanos completamente imprevisíveis, ilógicos, dominados pelas extravagâncias da livre imaginação. O senso de realidade e a percepção de um mundo objetivo e estável dependem, assim, em Hume, do poder ordenador da imaginação, das qualidades associativas que operam uma natural inclinação a certas ideias para se aglutinarem.

2 Émile Faguet (1847-1916), crítico literário e historiador francês, membro da Academia Francesa e colaborador em diversos periódicos literários parisienses, como o Journal des Débats e o La Revue de Paris. 
Essas qualidades, segundo Hume, são: semelhança, a passagem fácil de uma ideia a outra que lhe é similar. Através dessa qualidade, as noções de espécies animais, por exemplo, emergem; o que definiria, afinal, que diversos cavalos particulares fazem parte de uma mesma espécie geral, senão suas relações de semelhança? Outra qualidade é a contiguidade, a tendência a, ao evocarmos certas ideias, imaginar, naturalmente, outras ideias que se apresentaram à mente em relação de proximidade espacial ou temporal com as primeiras. Se imaginamos um acidente geográfico, um morro, por exemplo, é provável que os morros adjacentes compareçam às nossas mentes, sem grande esforço. Por último, há a relação de causa e efeito, a respeito da qual Hume (2000, p. 35) afirma que "nenhuma relação produz uma conexão mais forte na fantasia". Trata-se da transição fácil entre uma ideia e outra, que foi percebida, na experiência, como sempre presente, antes ou depois de seu aparecimento, constituindo, portanto uma causa ou efeito.

A imaginação, dessa forma, une ideias por percebê-las semelhantes, contíguas e causais/efeituais, mas essa união não se faz de forma abrupta e imediata. É por um lento progresso, pela repetição, pelo acúmulo temporal de experiências que o vínculo entre ideias se realiza. Quanto mais vezes observamos uma similaridade entre objetos, mais unidos estes se tornam na imaginação. Quanto mais vezes observamos uma relação de causa e efeito, mais sólida esta relação se torna. Daí a importância conferida por Hume ao Hábito ou Costume, descrito como o "guia da vida" (HUME, 2000, p. 690), aquilo que nos faz supor que o futuro será conforme nossas experiências passadas, dotando a vida de algum grau de previsibilidade.

As qualidades associativas, por fim, quando reforçadas pelo hábito, culminam na formação de Crenças. Para Hume, estas consistem em uma maneira especial de conceber as ideias na imaginação. Enquanto as ideias em que não cremos são experimentadas de maneira tíbia, aquelas investidas de assentimento ou crença são concebidas de maneira peculiar, mais intensa. Hume apela ao leitor para que sinta em si mesmo a diferença de intensidade entre crer e não crer, e explica a força com que concebemos uma ideia na qual cremos à transmissão de vividez que uma impressão presente aos sentidos ou à memória realiza, quando associada a esta ideia. Para ilustar este ponto, Hume recorre ao clássico exemplo da bola de bilhar:

Em virtude do hábito, minha mente passa do objeto visível, ou seja, uma bola movendo-se em direção a outra, a seu efeito usual, ou seja, o movimento da segunda bola. E não apenas concebe esse movimento, mas sente nessa concepção algo diferente de um mero devaneio da imaginação. (HUME, 2000, p. 691)

$\mathrm{O}$ ato de crer, em suma, consiste em imaginar com intensidade uma ideia, em cores vivas, vividez essa oriunda de uma impressão presente associada a tal ideia. Note-se a diferença entre as ideias vívidas da memória e as da imaginação. Estas últimas, que tomam a forma de crenças, não são lembradas, rememoradas. Crenças não são objetos de observação direta, pelo contrário, são suposições. Há uma sensível diferença entre nos lembrarmos de uma árvore que vimos e crer que esta mesma árvore estava lá, no mesmo local, ontem, está hoje ou estará amanhã.

Impressões, ideias, memória, imaginação e suas qualidades associativas, costume/hábito e crença. Eis as categorias fundamentais do modelo humeano aplicado ao tema do entendimento humano. Voltemo-nos agora às paixões.

\section{PAIXÕES}

O tema das paixões (ou sentimentos e afecções) foi um dos que mobilizou de forma quase unânime os pensadores identificados com os Iluminismos escocês e britânico. O tratamento que Hume dá a esse tema, porém, apresenta particularidades que tornam inadequada a ideia de que sua filosofia 
seria apenas uma continuação da tradição sentimentalista britânica, representada por nomes como o de Lorde Shaftesbury ou do Reverendo Francis Hutcheson.

Há, de fato, uma transição temática um tanto brusca no Tratado, do entendimento, no livro primeiro, às paixões, no livro segundo. $\mathrm{O}$ próprio Hume considera o segundo tema bastante mais fácil de entender que o primeiro (HUME, 2000, p. 697), mas a mudança de tema não implica mudança no modelo filosófico. Em relação ao entendimento, Hume, como vimos, nos oferece uma visão alternativa do empirismo, face ao realismo lockeano e sua premissa implícita (e por vezes explícita) de um mundo real independente da cognição humana; ora, em relação às paixões, Hume afasta-se de noção análoga, segundo a qual esse mesmo mundo real, objetivo, portaria harmonias e desarmonias, atributos intrínsecos a seus fenômenos e objetos que despertariam nos homens sentimentos de repulsa e agrado.

Para Hume, as paixões consistem em um tipo especial de impressão, distinta daquelas que nos afetam os órgãos dos sentidos. Estas últimas, Hume denomina Impressões de Sensação, enquanto as impressões delas derivadas, ou seja, impressões de segunda ordem, como as paixões, são Impressões de Reflexão. Nas palavras de Hume,

Impressões originais ou de sensação são as que surgem na alma sem nenhuma percepção anterior, pela constituição do corpo ... ou pela aplicação dos objetos sobre os órgãos externos. As impressões secundárias ou reflexivas são as que procedem de algumas dessas impressões originais, seja imediatamente, seja pela interposição de suas ideias. (HUME, 2000, p. 309)

Paixões, por esse prisma, não são impressões originais, isto é, produzidas por nossa experiência direta com o mundo externo, mas produtos derivados dessas experiências primárias. Em resumo, paixões são impressões de impressões. Essa proposição, que pode parecer trivial, encerra implicações importantes: as paixões humanas não possuem mais como lastro os objetos e fenômenos fixos e objetivos do mundo real, mas "meras" impressões, de maneira que a oscilação e a volatilidade das impressões de sensação explicam e fundamentam a oscilação e a volatilidade das paixões; em outras palavras, o modelo humeano introduz nesse tema um importante princípio de relativização, segundo o qual um mesmo objeto, fenômeno ou evento pode despertar, em momentos diferentes, diferentes paixões, uma vez que não há objetos, fenômenos e eventos, no sentido estático e puramente objetivo, como supunham, por exemplo, as filosofias de Shaftesbury e Hutcheson, analisadas por Cachel (2014).

Não são de atributos objetivos que emergem nossa repulsa ou nosso agrado; não mais das belezas e fealdades intrínsecas à realidade, mas das efêmeras impressões de sensação, do modo como sentimos, enxergamos, percebemos, em um momento particular, de um ponto de vista particular, em circunstâncias particulares e, sobretudo, relativas, os supostos objetos e eventos contidos no "mundo externo".

Dentre as impressões de sensação, duas são consideradas cruciais, por Hume, por darem origem a um conjunto bastante grande de paixões: prazer e dor. O processo pode ser resumido da seguinte forma: sentimos, por motivos os mais diversos, dores e prazeres de diversos tipos; em seguida, essas dores e prazeres convertem-se em ideias na mente, que, por sua vez, produzem novas impressões, tais como desejo, aversão, medo, esperança, orgulho, humildade, etc. Tomemos como exemplo um objeto cortante qualquer que nos tenha ferido em algum momento do passado. Ao evocarmos a ideia da dor que nos foi imposta pelo objeto, é possível que sejamos tomados do sentimento de aversão a esse objeto; se este estiver muito próximo de nós, talvez sejamos tomados também do medo de sermos novamente feridos.

No exemplo acima, a situação é bastante simples, e são poucos os elementos envolvidos: basicamente, o sujeito ferido e o objeto. Hume, no entanto, ao tratar das paixões, apresenta uma série de situações de maior complexidade, das quais emergem outras paixões, como o orgulho, a humildade, o amor, o ódio, a benevolência, a raiva e outras mais. Em todos esses casos há uma combinação complexa de ideias envolvidas na produção das paixões. Nos casos em que o orgulho aflora, a ideia que uma pessoa tem de si encontra-se associada a outras ideias, de qualidades físicas ou mentais. Juntas, as 
ideias de si mesmo e das qualidades (beleza, inteligência etc.) concorrem para produzir a impressão de reflexão que designamos orgulho, e o mesmo processo, mas em chave invertida, dá origem à humildade.

\section{MORAL}

A abordagem humeana ao problema da moralidade não foge ao método que até aqui tenho buscado destacar, destoante do empirismo lockeano. A questão preliminar que Hume dispõe sobre a moral é: será por meio da razão ou dos sentimentos que somos capazes de distinguir entre ações dignas de louvor e outras, dignas de reprovação? (HUME, 2003, p. 226).

Hume reconhece que a razão desempenha papel relevante na formação de nossos juízos morais. Seja pela investigação rigorosa de fatos, seja através de raciocínios abstratos, os homens a mobilizam para realizar seus julgamentos em relação ao vício e à virtude; no entanto, a palavra final nesses julgamentos, é proferida pelo sentimento, pois "O que é inteligível, evidente, provável, verdadeiro, obtém somente a fria aquiescência do entendimento" (HUME, 2003, p. 229). As verdades que alcançamos através de uma cadeia de observações ou raciocínios, como as da matemática, não são capazes de despertar propensões em favor ou desfavor de uma ação qualquer, segundo Hume. Se descobrirmos, ao cabo de uma investigação, que um homem assassinou outro, por exemplo, trata-se de uma verdade obtida por meios racionais, mas se não sentirmos algo pelo homem morto, se formos completamente indiferentes ao seu destino, é certo também, que não se formará em nós qualquer ideia de vício ou virtude acerca do ato (o homicídio) e seu agente.

Hume distancia-se, como se vê, da tradição racionalista em assuntos morais, mas não se adequa integralmente à filosofia moral sentimentalista britânica, representada, principalmente, por Butler, Shaftesbury e Hutcheson, embora herde deles o destaque conferido aos sentimentos morais. A abordagem de Hume se distingue da de seus antecessores britânicos em um ponto chave, o do local de ocorrência do fenômeno moral. Todos os três precursores aludidos situam o fenômeno moral nas ações das pessoas, isto é, de terceiros, ações essas que uma vez percebidas por nós, os espectadores, atingem um suposto sentido moral que possuímos dentro de nós, análogo aos órgãos dos sentidos.

Hume desloca o local de ocorrência da moralidade, das ações de terceiros, isto é, da realidade supostamente objetiva que nos circunda, para a sensibilidade subjetiva, para o atributo comum a todos os seres humanos de se afetar por impressões, no curso da experiência. A analogia entre os órgãos dos sentidos e o sentido moral, que corresponderia a uma espécie de sexto órgão do sentido, já não convém ao modelo humeano, pois não há ações viciosas ou virtuosas em si, de maneira absoluta.

Observei na seção anterior, a respeito das paixões que, para Hume, elas derivavam de impressões anteriores, advindas dos sentidos, podendo ser classificadas como impressões de impressões, ou impressões secundárias. Acrescentei que essa formulação humeana portava consequências relativistas, pois nossas paixões poderiam variar de acordo com nossas voláteis impressões, não estando mais atreladas a um mundo externo sólido e regular.

A aproximação de Hume à questão da moralidade, repito, comunga da mesma rejeição ao "mundo real" como princípio explicativo que verificamos no tratamento das paixões, mas um aspecto dos fenômenos morais torna-o mais complexo e demandante de uma interpretação específica, diferente da teoria das paixões e sentimentos comuns. Ora, enquanto estes últimos originam-se de impressões de sensação, isto é, de percepções sensoriais, especialmente das dores e prazeres que experimentamos, o sentimento moral origina-se de dores, prazeres, paixões e sentimentos em geral que julgamos observar nos outros.

Esse aspecto pode ser elucidado se evocarmos o caso da ingratidão, analisado por Hume. A ingratidão não é um fato, tampouco uma ação que possamos perceber com clareza. Hume conclama: 
onde está o fato que aqui consideramos questionável; procuremos apontá-lo, determinar o momento de sua ocorrência, descrever sua natureza ou essência, explicar o sentido ou faculdade que o apreende. (HUME, 2003, p. 270)

Frustradas essas tentativas, Hume conclui que a ingratidão reside na mente da pessoa ingrata, e dessa forma, não podemos percebê-la. Note-se que, se não podemos perceber diretamente a ingratidão, por conseguinte, nosso sentimento de que ela é um vício não decorre de uma apreensão pelos sentidos, como no caso das paixões, em que uma visão, um cheiro, uma dor, etc, podem despertá-las diretamente.

O que então, podemos nos perguntar, está na base de nossos sentimentos morais? Se não são percepções de sensação, como visões, cheiros e dores, quais são os elementos que despertam em nós a aprovação, o louvor, a admiração ou a reprovação e o desprezo?

Em primeiro lugar, vício e virtude são atribuídos não a fatos ou ações, mas a qualidades mentais:

É evidente que, quando elogiamos uma determinada ação, consideramos apenas os motivos que a produziram, e tomamos a ação como signo ou indicador de certos princípios da mente e do caráter. A realização externa não tem nenhum mérito. Temos de olhar para o interior da pessoa para encontrar a qualidade moral. (HUME, 2000, p. 517, grifo nosso)

Essas qualidades, como a benevolência, a gratidão e a generosidade, são atribuídas aos indivíduos em função de ações que desencadeiam sentimentos agradáveis em outros indivíduos. Suponhamos que vemos um morador de rua recebendo atenção e um prato de comida de um transeunte. Por supormos que o morador de rua sente algum conforto, supomos que o transeunte agiu com benevolência. Em resumo, o fenômeno moral depende de (I) um ou mais agentes morais, ao qual atribuímos certas qualidades mentais, (II) um ou mais pacientes, aqueles que são alvo de uma ação virtuosa ou viciosa, (III) um ou mais observadores dessas situações, que são tocados por sentimentos morais e expressam aquilo que sentem, na forma de louvores e reprimendas.

Neste ponto, uma questão fundamental se impõe: se apenas supuséssemos, de maneira racional, que o morador de rua sentira algo de agradável no caso exposto, provavelmente, não seríamos tomados, nós, os observadores da cena, de um sentimento moral, e, por conseguinte, permaneceríamos indiferentes à cena. Como é possível, então, que aquilo que os outros sentem, aquilo que diz respeito, aparentemente, apenas à sua interioridade, reflita em nós, os observadores, mobilize nossa sensibilidade e faça aparecer em nós os sentimentos morais?

A resposta pode ser encontrada na faculdade da simpatia, da qual todos os seres humanos são dotados, e que "nos leva a sair de nós mesmos, proporcionando-nos tanto prazer ou desprazer ante caracteres que sejam úteis ou nocivos à sociedade quanto teríamos se eles favorecessem nosso próprio benefício ou prejuízo" (HUME, 2000, p. 618). Através da simpatia, podemos sentir em nossos peitos as dores, angústias, prazeres e alegrias alheias; não, claro, em sua totalidade, mas algo dessas impressões alheias nos é transmitido pelas mãos da simpatia.

Como apontou Guimarães (2007), por sermos dotados naturalmente dessa faculdade, não são os rigores dos códigos de preceitos morais, como o Decálogo, mas os retratos pungentes, contidos na História, na Literatura e nas narrativas orais, que logram cultivar a sensibilidade moral e aproximar os indivíduos de outros, até então sentidos como distantes no espaço e no tempo, ampliando dessa forma o escopo, naturalmente restrito, da simpatia.

A centralidade da simpatia na filosofia social de Hume a coloca em polo oposto àquelas assentadas na noção de que as paixões egoístas e os interesses são os motores ocultos de toda e qualquer ação aparentemente virtuosa e benévola. Segundo Cerqueira (2008), Thomas Hobbes e Bernard Mandeville foram os principais articuladores, no contexto da filosofia moderna, dessa visão da natureza humana impulsionada pelo amor-próprio. A condição natural do homem, para esses autores, não é de 
sociabilidade, de convívio pacífico e previsível, mas de disputa e desconfiança constantes, aplacadas apenas pelo estabelecimento do governo, isto é, de um ente artificial, dotado de força suficiente para evitar os conflitos de interesses inerentes à condição originária dos homens.

A tendência natural à simpatia atua, no modelo humeano, como contraponto ao reinado do amor-próprio e está na raiz da concepção de que há sociabilidade anterior à emergência das regras de justiça e do governo. Na verdade, estes últimos teriam surgido, segundo Hume, para suprir as fraquezas originárias da simpatia, pois parece mais fácil simpatizarmo-nos com aqueles que estão próximos de nós, com nosso círculo íntimo, digamos, do que com aqueles que estão distantes e que pouco conhecemos; o estabelecimento das regras de justiça ampliaria artificialmente o alcance da simpatia, impelindo os indivíduos a respeitar as posses de pessoas desconhecidas, anônimas. Desse modo, a "falha" na simpatia primitiva é corrigida, conservando a estabilidade das relações sociais e promovendo um estado de coisas sentido, de forma geral, como benéfico, útil e agradável ao conjunto social.

Justiça e obediência civil podem ser compreendidas, portanto, como integrantes de um tipo específico de virtude, distinto daquelas que afloram naturalmente nos homens, quando contemplam certas ações. Nesse caso, estamos diante de virtudes artificiais, estabelecidas pelos homens no curso de suas vidas, em seu anseio por viver "melhor e mais prazerosamente" (KIRALY, 2010 p. 127). Um critério razoavelmente nítido de demarcação entre virtudes naturais e artificiais pode ser estipulado a partir da observação de Kiraly (2010, p. 127) de que "sempre que possuímos necessidade de estabelecimento de uma sanção para regular condutas, estamos diante de artifício."

\section{CONCLUSÃO}

Ao longo deste texto, busquei apresentar as linhas gerais daquilo que no início intitulei "modelo humeano"; ao fazê-lo, creio que abordei um conjunto amplo e variado de questões, no interior dos três grandes temas humeanos: entendimento, paixões e moral. No vasto oceano de problemas filosóficos que Hume se dispôs a investigar, busquei eleger como objeto específico, ou, para preservar a metáfora marítima, como bússola, a reconfiguração singular do empirismo que Hume realizou, por meio de suas investigações. Sustentei que, nas reflexões em torno dos três grandes temas, Hume afastou-se da versão lockeana do empirismo, especialmente de sua concepção de um mundo real, objetivo e da ideia correspondente de que os seres humanos são espectadores, mais ou menos atentos e cuidadosos dessa realidade que se descortina aos nossos sentidos.

Uma extensa literatura consolidou-se, nas últimas décadas, acerca de questões específicas do pensamento de Hume, como a identidade pessoal, a justificação filosófica das crenças, a emergência das regras de justiça, etc. Optei, neste ensaio, por abordar um eixo transversal amplo, que atravessa diversas questões e vincula os três grandes temas de sua obra: entendimento, paixões e moral. Não creio que o empirismo alternativo de Hume seja o único elo entre as diferentes partes de seu modelo, mas certamente é um dos mais relevantes, e cuja identificação pode nos oferecer uma profícua chave de leitura de sua obra.

Quando afirmo que o empirismo singular de Hume atravessa os grandes temas e os conecta, refiro-me ao fato de que a concepção humeana de entendimento tem desdobramentos no exame das paixões e da moral e vice-versa. Sua versão alternativa do empirismo não apenas não se limita a qualquer um dos temas, como transmite efeitos de uns para outros. Veja-se o caso da simpatia, uma faculdade distintiva do empirismo humeano, fundamental no âmbito da moral, mas que, como Guimarães (2007) indica, exerce também efeitos notáveis sobre o entendimento, constituindo, por vezes, requisito para se obter conhecimento factual verdadeiro. Especialmente nas obras posteriores ao Tratado, Guimarães identifica na simpatia um dos elos integradores entre as esferas do pensamento humeano: "a simpatia adquire uma função epistêmica: simpatia pelos personagens e práticas é condição para o estudo dos fenômenos históricos e políticos" (GUIMARÃES, 2007, p. 204-205) 
A tradição do empirismo lockeano manteve-se, foi cultivada e reelaborada ao longo dos séculos XIX e XX, por intelectuais vinculados a diversas tendências na filosofia e nas ciências sociais, de forma geral: positivismo, positivismo lógico, behaviorismo, escolha racional, etc. Ao afirmar que Hume se distingue dessa linhagem empirista, não busco me alinhar a certas interpretações do modelo humeano que o veem como destrutivo, negador de toda possibilidade de conhecimento do mundo, radicalmente cético etc. (ARRUDA, 2014, p. 20), mas apenas chamar atenção para o fato de que as teorias cognitivas, passionais e morais de Hume podem ser importantes fontes de inspiração para rotas epistemológicas alternativas nas humanidades. 


\section{Referências}

ALDRICH, Virgil. Locke's theory of perception. Rice Institute Pamphlet, Houston, v. 20, n. 2, 1933. Disponível em https://scholarship.rice.edu/handle/1911/8905. Acesso em 05/08/2020.

ARRUDA, Hugo. O Experimento [de] Hume: algumas palavras sobre a maneira como David Hume apresentou a distinção entre sentir e pensar em seu Tratado da Natureza Humana. 160 f. Dissertação (Mestrado em Ciência Política) - Programa de Pós-graduação em Ciência Política, Universidade Federal Fluminense, Niterói, RJ. 2014.

BERLIN, Isaiah. The Roots of Romanticism. New Jersey: Princeton University Press, 1999.

CACHEL, Andrea. Beleza e Moralidade em Shaftesbury e Hutcheson. Revista Ética e Filosofia Política, Juiz de Fora, v. I, n. XVII, ago. 2014. Disponível em http://www.ufjf.br/eticaefilosofia/files/2009/08/17_1_cachel.pdf. Acesso em 20/12/2017.

CERQUEIRA, Hugo. Sobre a filosofia moral de Adam Smith. Síntese - Revista de Filosofia, Belo Horizonte, v. 35, n. 111. 2008. Disponível em http://www.faje.edu.br/periodicos/index.php/Sintese/article/view/158/279. Acesso em $23 / 12 / 2017$.

DESCARTES, Rene. Meditações Metafísicas. Tradução de Maria Ermantina de Almeida Prado Galvão. São Paulo: Martins Fontes, 2005.

DEWEY, John. The Quest for Certainty: A study of the relation of knowledge and action. New York: Minton, Balch \& Co, 1929.

DUIGNAN, Brian; QUINTON, Anthony; QUINTON, Baron et al. Empiricism. Encyclopædia Britannica, 2016. Disponível em https:/www.britannica.com/topic/empiricism. Acesso em 20/12/2017.

GUIMARÃES, Lívia. Simpatia, moral e conhecimento na filosofia de Hume. Doispontos, Curitiba, v. 4, n. 2 , out. 2007. Disponível em http://revistas.ufpr.br/doispontos/article/view/8185/8131. Acesso em 24/12/2017.

HUME, David. Tratado da Natureza Humana. Tradução de Deborah Danowski. São Paulo: Unesp, 2000.

HUME, David. Investigações sobre o entendimento humano e sobre os princípios da moral. Tradução de José Oscar de Almeida Marques. São Paulo: Unesp, 2003.

HUME, David. Ensaios Morais, Políticos e Literários. Tradução de Luciano Trigo. Rio de Janeiro: Topbooks, 2004.

KIRALY, Cesar. Os Limites da Representação: um ensaio desde a filosofia de David Hume. São Paulo: Giz Editorial, 2010.

LESSA, Renato. A condição hum(e)ana e os seus Ensaios. In: HUME, David. Ensaios Morais, Políticos e Literários. Rio de Janeiro, Topbooks, 2004, p. 11-46.

LOCKE, John. An Essay Concerning Human Understanding. Oxford: Clarendon Press, 1975.

MALHERBE, Michel. La Philosophie Empiriste de David Hume. Paris: Librairie Philosophique J VRIN, 1992.

MONTEIRO, João Paulo. Hume e a Epistemologia. São Paulo: Unesp, 2009.

POPPER, Karl. Objective Knowledge: An Evolutionary Approach. Oxford: Clarendon Press, 1972.

PRICE, Henry. Hume`s Theory of The External World. Oxford: Clarendon Press, 1940.

REID, Thomas. Essays on the Intellectual Powers of Man. University Park: Pennsylvania State University Press, 2002.

SARTRE, Jean-Paul. A Imaginação. Tradução de Paulo Neves. Porto Alegre: L\&PM, 2008. 
ZAHREDDINE, Stephanie. Hume e o problema da justificação da resistência ao governo. In: CONTE, Jaimir; FERRAZ, Marília; ZIMMERMANN, Flávio (Orgs.) Ensaios sobre a filosofia de Hume. Florianópolis: NEL/UFSC, 2016 , p. 39-60.

$\begin{array}{cl}\text { Histórico } & \begin{array}{l}\text { Recebido em: 03/04/2018 } \\ \text { Revisado em: } 22 / 06 / 2020 \\ \text { Aceito em: } 19 / 07 / 2020\end{array} \\ \text { Financiamento } & \begin{array}{l}\text { O autor é bolsista CAPES em estágio pós-doutoral no Programa de Pós-graduação } \\ \text { em Políticas Públicas, Estratégias e Desenvolvimento da Universidade Federal do Rio } \\ \text { de Janeiro. }\end{array}\end{array}$

